\title{
The superficial radial nerve: techniques for evaluation
}

\author{
J F CRITCHLOW, M E SEYBOLD, AND C J JABLECKI \\ From the Beth Israel Hospital, Boston, Harvard Medical School, Boston, The San Diego VA Medical \\ Center, San Diego, and The University of California, San Diego
}

SUMMARY Several methods for obtaining radial nerve sensory responses have been compared. A technique for antidromic latency measurement over a fixed distance most consistently produced responses which were easy to obtain, reliable and well tolerated by the subjects.

The radial nerve may be damaged by trauma along its rather exposed course and by toxins or vascular lesions due to systemic disease. Electrophysiologic evaluation of radial nerve function has been performed, but with many different methods and varying results. ${ }^{1-5}$

Measurement of motor conduction velocity of the radial nerve was described first by Gassel and Diamontopoulos ${ }^{6}$ and by Jebsen. ${ }^{7}$ Downie and Scott $^{1}$ measured conduction of radial sensory fibres in the forearm, finding a velocity similar to that of the median and ulnar nerves, but a very low amplitude of response (average 3.8 $\mu \mathrm{v}$ ). Other techniques have used different anatomical landmarks (the proximal phalanx of the thumb, ${ }^{4}$ the "anatomical snuffbox,"2 the wrist;"), have employed either needle ${ }^{5}$ or skin electrodes ${ }^{248}$; and have differed as to the distance over which the measurement is made. Feibel and Foca ${ }^{4}$ used a set distance of $11 \mathrm{~cm}$ for measurement of distal latency, but reported low amplitudes of response $(6 \cdot 6 \pm \mu \mathrm{v})$.

The present study was undertaken with the aim of developing a method for determining radial nerve sensory responses which would be technically simple to perform, relatively painless, and give reliable recordings of sufficiently high amplitude to avoid the need for an electronic averager.

\section{Materials and methods}

A TECA TE4 electromyograph (White Plains, New York) was used to elicit and record responses on photosensitive paper for measurement. The high frequency filter setting was $3 \cdot 2 \mathrm{KHz}$; the low frequency filter setting, $32 \mathrm{~Hz}$.

Address for reprint requests: Dr ME Seybold, San Diego VA Medical Center, 3350 La Jolla Village Drive, San Diego, CA 92161, USA

Accepted 11 April 1980
Temperature was measured with an electronic needle probe thermistor (Rochester Electro-Medical, Osseo, Minnesota) inserted in the body of the first dorsal interosseus muscle. Temperatures over $32.5^{\circ} \mathrm{C}$ were considered normal. Subjects with low temperatures had their arms warmed for 10 minutes in a water bath $\left(40^{\circ} \mathrm{C}\right)$ and the temperature checked again before study. Stimulation was delivered with a handheld two-pronged stimulator (TECA); responses were recorded with $6 \mathrm{~mm}$ tin disc surface electrodes. Ground contact was established with a $2 \cdot 5 \times 2 \cdot 5 \mathrm{~cm}$ lead plate.

\section{Technique}

Method I-The measurement of antidromic sensory action potentials is shown in fig 1 . This is a modification of the method of Downie and Scott. ${ }^{2}$ A branch of the superficial radial nerve was palpated over the extensor pollicis longus tendon in the "anatomical snuffbox" approximately $3 \mathrm{~cm}$ distal to the radial styloid. The skin surface was cleaned with alcohol and a disc electrode $\left(G_{1}\right)$ was placed directly

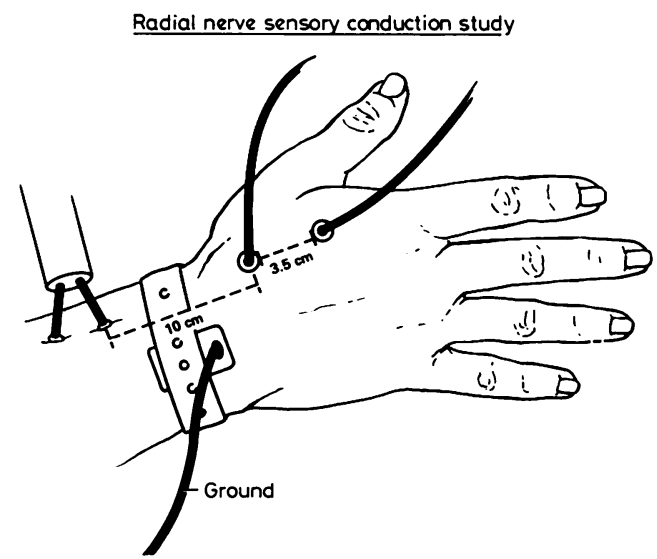

Fig 1 Electrode placement for antidromic radial sensory conduction study (Method I). 
on the nerve and secured with tape. If more than one branch was palpated the largest branch was used. A reference disc electrode $\left(G_{2}\right)$ was placed $3.5 \mathrm{~cm}$ distal to $G_{1}$ over the body of the first dorsal interosseus muscle. The ground plate was placed over the dorsum of the wrist. Stimuli were applied with the bipolar stimulator on the dorsal lateral aspect of the radius, the cathode being nearest to and $10 \mathrm{~cm}$ proximal to the $G_{1}$ disc. In most subjects the superficial radial nerve was palpable at the stimulation site.

The intensity of the electrical stimulus was increased until the maximal response was obtained (range 50-250 volts, $0 \cdot 05-0 \cdot 1 \mathrm{~ms}$ ). An intensity about $20 \%$ greater was chosen for supramaximal stimulation strength. Three super-imposed responses were recorded. By convention the distal latency was measured from onset of stimulation to the peak of the negative response and amplitude was measured peak to trough of the typical triphasic response (fig 2). A stimulus delay of $1 \mathrm{~ms}$ was used to permit accurate determination of the time of the onset of the stimulus.

Method II-Orthodromic responses were recorded using the same electrode positions as in Method I except that discs over the snuffbox were employed as stimulation electrodes, and recording discs replaced the stimulator probes over the dorsal lateral radius. The cathode to $G_{1}$ distance was still $10 \mathrm{~cm}$, and $G_{1}$ to $G_{2}$ distance was $3 \cdot 5 \mathrm{~cm}$.

Method III-Antidromic stimulation was performed using a method similar to that of Shanhani et al. ${ }^{8}$ The radial nerve was stimulated as in Method I and the response was recorded with two steel finger clip electrodes $1 \mathrm{~cm}$ apart (Rochester Electro-Medical) on the proximal phalanx of the thumb.

Method IV-Orthodromic sensory potentials were elicited in a similar manner as in Method III except that the clip electrodes on the thumb were used as stimulation electrodes, the more proximal electrode acting as the cathode.

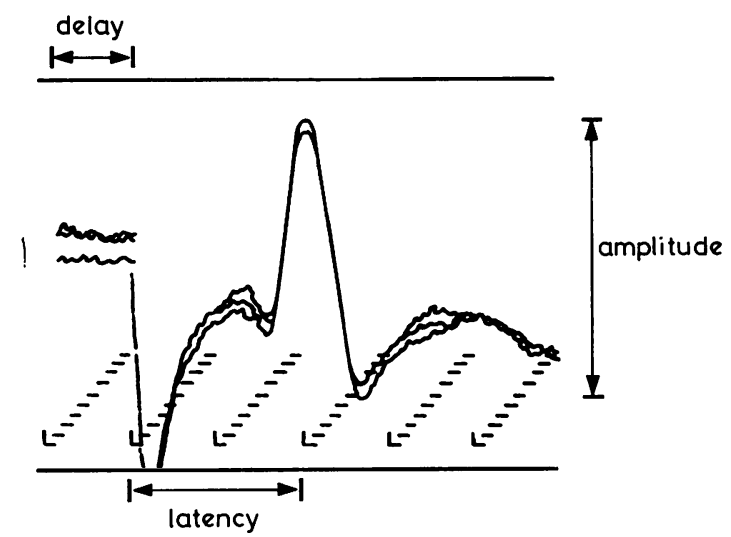

Fig 2 Radial sensory response recorded by Method $I$.
Median and ulnar responses

Median and ulnar nerve sensory potentials were recorded using orthodromic stimulation applied through clip electrodes attached to the proximal and middle phalanx of the index finger for median responses, and corresponding locations on the little finger for ulnar responses. Disc recording electrodes $\left(G_{1}\right)$ were placed on the wrist along the nerve tract at distances of $13 \mathrm{~cm}$ and $11 \mathrm{~cm}$ respectively for median and ulnar recordings. The reference electrode $\left(G_{2}\right)$ was located $3 \cdot 5 \mathrm{~cm}$ proximal to $G_{1}$.

\section{Subject population}

Subjects were laboratory personnel and patients referred to the Clinical Neurophysiology Laboratories at the Veterans Administration Hospital and the University Hospital in San Diego, California. Subjects were excluded from the normal population if they had a history of uraemia, diabetes, alcohol abuse, or if they showed electromyographic evidence of cervical radiculopathy, polyneuropathy or radial neuropathy.

In the study of comparison of methods, data was analysed on a paired basis with no inferences as to mean values. In this study both normal and "abnormal" subjects were included.

\section{Results}

Comparison of Methods I-IV The amplitudes of the sensory potentials of 13 radial nerves (nine subjects) studied with the four different methods were compared. Some patients with radial nerve lesions were included in this preliminary study (table 1). The amplitudes of the responses recorded by Method I were greater than those recorded by Methods III and IV $(p<0.0005)$. There was a trend for the amplitude of the radial sensory response to be greater with Method I

Table 1 Comparison of Methods I-IVAmplitude of Response

\begin{tabular}{lllll}
\hline Subject & \multicolumn{2}{l}{ Response $($ in $\mu v)$} & \\
\cline { 2 - 5 } & $I$ & $I^{*}$ & $I I \dagger \dagger$ & $I V \ddagger$ \\
\hline MD & 26 & 23 & 6 & 7 \\
& 32 & 19 & 5 & 5 \\
BW & 22 & 19 & 5 & 6 \\
& 16 & 22 & 5 & 6 \\
JC & 16 & 14 & 7 & 10 \\
MC & 20 & 15 & NR & NR \\
CJ & 32 & 74 & 13 & 18 \\
AM & 12 & NR & NR & NR \\
& 7 & 6 & NR & NR \\
GS & 60 & 84 & 13 & 12 \\
MP & 50 & 25 & NR & 7 \\
& 40 & 34 & 10 & 10 \\
WN & 42 & 34 & 5 & 8 \\
\end{tabular}

NR $=$ no response

*= The difference between $I$ and II is not statistically significant by paired $t$-test. $\mathrm{p}>0.4(t=0.1$ at $12 \mathrm{df})$

$\dagger=$ I $>$ III $\mathrm{p}<0.0005$ by paired $t$-test $(t=6.1$ at $12 \mathrm{df})$ $\ddagger=\mathrm{I}>\mathrm{IV} \mathrm{p}<0.0005$ by paired $t$-test $(t=6.2$ at $12 \mathrm{df})$ 
(11/13 nerves) compared to Method II, but the mean for the two groups was not different (p>0.4).

Comparison of Methods I and II Methods I and II were chosen to study a total of 86 radial nerves (45 subjects). The mean amplitude of the response by Method I $(35.5 \mu \mathrm{v})$ was greater $(\mathrm{p}<0.005)$ than that obtained by Method II $(30 \cdot 1 \mu \mathrm{v})$. In addition, Method I showed less variability between subjects as judged by a lower standard error of the mean $(1.2 \mu \mathrm{v}$ versus 1.7 $\mu v)$. There was no difference $(p>0.5)$ between the mean amplitude of the right and left radial sensory responses in 36 normal subjects with either Method I or II. However, there was less variability between sides with Method I as judged by the mean of the differences between the right and left responses which was $0.5 \mu \mathrm{v}$ with Method I and $2.8 \mu \mathrm{v}$ with Method II. Whereas Method I and Method II differed in the amplitude of the responses, the mean \pm SD of the peak latency recorded by Method I $(2 \cdot 12 \pm 0.14 \mathrm{~ms})$, was not different $(\mathrm{t}=0.8$ at $85 \mathrm{df}, \mathrm{p}=>0.4)$ from that recorded by Method II $(2 \cdot 11 \pm 0 \cdot 15 \mathrm{~ms})$. Thirtythree normal subjects were asked if Method I or Method II was more uncomfortable or if there was no difference. Thirty of 33 stated that orthodromic stimulation (Method II) was considerably more uncomfortable than antidromic stimulation (Method I) one believed antidromic to be more painful, and two could appreciate no difference. These data are summarised in table 2.

Normal values Based on these results, Method I was selected to study 98 radial nerves in 58 normal subjects (ages 20 to $77 \mathrm{yr}$ ) to determine the normal range and variability of the amplitude and peak latency. The mean amplitude was $35.4 \mu \mathrm{v} \pm 11 \mu \mathrm{v}$. The latency ranged from 1.8 to $2 \cdot 4 \mathrm{~ms}$ with a mean \pm SD of $2 \cdot 11 \pm 0.15 \mathrm{~ms}$.

A graph of the latency values against age by decade showed a trend for the latency to increase with increasing age (fig 3), a trend confirmed by a linear regression calculation with a correlation

Table 2 Comparison of antidromic (I) and orthodromic (II) stimulation

\begin{tabular}{|c|c|c|}
\hline & $\begin{array}{l}\text { Method I } \\
\text { (antidromic) }\end{array}$ & $\begin{array}{l}\text { Method II } \\
\text { (orthodromic) }\end{array}$ \\
\hline $\begin{array}{l}\text { Amplitude* } \\
\text { Difference in amplitude } \\
\text { right vs left arms }\end{array}$ & $\begin{array}{r}35 \cdot 5 \mu \mathrm{v}(\text { SEM 1.2) } \\
0.5 \mu \mathrm{v}(\text { SEM 1.7) }\end{array}$ & $\begin{array}{r}30 \cdot 1 \mu \mathrm{v}(\text { SEM 1·7) } \\
-2 \cdot 8 \mu \mathrm{v}(\text { SEM 2.3) }\end{array}$ \\
\hline $\begin{array}{l}\text { Latency } \dagger \\
\text { Discomfort } \ddagger \\
\text { (more uncomfortable me }\end{array}$ & $\begin{array}{l}2 \cdot 12 \text { ms (SD 0 } 14) \\
1 / 33 \text { subjects } \\
\text { hod) }\end{array}$ & $\begin{array}{l}2 \cdot 11 \text { ms (SD 0 } 16) \\
30 / 33 \text { subjects }\end{array}$ \\
\hline
\end{tabular}

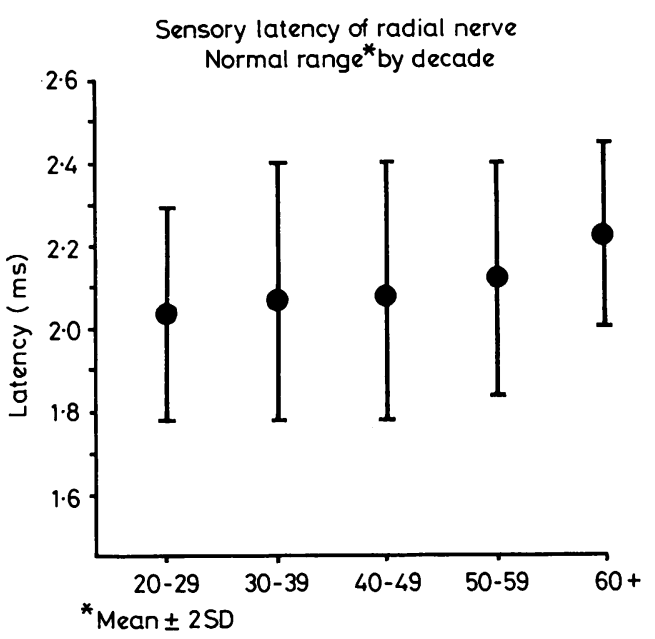

Fig 3 Relationship of the amplitude and latency of the radial sensory response to age.

coefficient (R) of $0 \cdot 92$. Calculation of the difference between the amplitude and latency of the right and the corresponding values of the left radial nerves of 44 subjects, when expressed as a percentage of the larger value, demonstrated that the maximum amplitude difference was always less than $50 \%(18 \pm 12 \%)$ and the maximum latency difference was always less than $10 \%(4 \pm 3 \%)$. Comparison by paired $t$-test of sensory responses of the radial nerve with those of the median and ulnar nerves from the same subjects showed that the amplitude of antidromic sensory responses of the radial nerve was larger $(p<0.0005)$ than that of either the median or ulnar orthodromic responses (table 3 ).

\section{Discussion}

A simple, reliable, relatively comfortable technique for measuring sensory conductions of the superficial sensory branch of the radial nerve has been described (Method I). This study has

Table 3 Comparison of median, ulnar, and radial sensory responses

\begin{tabular}{ll}
\hline Nerve & $\begin{array}{l}\text { Amplitude } \\
(\text { mean } \pm S D)\end{array}$ \\
\hline Radial $(\mathrm{N}=42)$ & $36 \pm 11 \mu \mathrm{v}$ \\
Median $(\mathrm{N}=42)$ & $21 \pm 6 \mu \mathrm{v}$ \\
Ulnar $(\mathrm{N}=41)$ & $12 \pm 7 \mu \mathrm{v}$
\end{tabular}

The radial sensory responses were obtained with Method I and the median and ulnar responses by the orthodromic technique described in the Methods. Analysis of the difference between pairs by the Student $t$-test showed that the radial nerve response amplitude was greater $(p<0.0005)$ than the median and ulnar nerve response amplitudes with $t=9 \cdot 4$ and $16 \cdot 7$, respectively 
Table 4 Comparison with other investigators (normal subjects)

\begin{tabular}{|c|c|c|c|c|}
\hline & $\begin{array}{l}\text { Mean } \\
\text { amplitude }\end{array}$ & $\begin{array}{l}\text { Distal } \\
\text { latency }\end{array}$ & Distance & $\begin{array}{l}\text { Averager } \\
\text { use }\end{array}$ \\
\hline $\begin{array}{l}\text { Method I } \\
\text { Trojaborgs }\end{array}$ & $\begin{array}{l}35 \cdot 4 \mu v \\
13 \cdot 1 \mu v\end{array}$ & $\begin{array}{l}1 \cdot 8-2.4 \mathrm{~ms} \\
\text { reported con } \\
\text { velocity }\end{array}$ & $\begin{array}{l}10 \mathrm{~cm} \\
\text { duction }\end{array}$ & $\begin{array}{l}\text { no } \\
\text { yes }\end{array}$ \\
\hline $\begin{array}{l}\text { Feibel } 4 \\
\text { Shahani } 8 \\
\text { Downie }^{1}\end{array}$ & $\begin{array}{r}6.6 \mu v \\
21.4 \mu v \\
3.8 \mu v\end{array}$ & $\begin{array}{l}1 \cdot 2-2 \cdot 8 \mathrm{~ms} \\
2 \cdot 0-3 \cdot 3 \mathrm{~ms} \\
4 \cdot 2-7 \cdot 1 \mathrm{~ms}\end{array}$ & $\begin{array}{l}11 \mathrm{~cm} \\
11-18 \mathrm{~cm} \\
\text { wrist- } \\
\text { spiral groove }\end{array}$ & $\begin{array}{l}\text { yes } \\
\text { no } \\
\text { no }\end{array}$ \\
\hline Downie ${ }^{2}$ & $11.4 \mu \mathrm{v}$ & $1.8-3.2 \mathrm{~ms}$ & $8-16 \mathrm{~cm}$ & no \\
\hline
\end{tabular}

dealt only with measurements of the amplitude and distal latency of the response over a fixed distance. No attempt has been made to convert the results to a conduction velocity to avoid the introduction of error which is compounded in calculations using short $(10 \mathrm{~cm})$ conduction distances.

The responses derived from Methods I and II were of higher amplitude than those from Methods III and IV (table 1). Using techniques similar to Methods III and IV, Shahani et $a l^{8}$ found the mean amplitude of response to be $21.4 \mu \mathrm{v}$. Direct comparison of mean amplitude of response recorded by Method III in this study with the mean amplitude reported by Shahani et $a l^{8}$ is not possible because certain subjects in this part of our study were not from the normal group.

The findings of orthodromic and antidromic radial sensory stimulation with identical electrode locations are in general agreement with the literature. ${ }^{248}$ The antidromic technique (Method I) was superior to the orthodromic technique (Method II) because it was more comfortable, the amplitude of response was greater and there was less intrasubject and intersubject variation.
The peak latency values obtained by the two techniques were identical. In our experience there were a few subjects (none from the normal group) with recordable antidromic responses in whom an orthodromic response could not be elicited. The converse situation was never seen.

Results obtained by Method I are compared to those of other investigators in table 4. In addition to a higher mean amplitude of response, the technique described in this report does not require the use of averaging modules or constant temperature control and avoids the variability inherent in orthodromic radial nerve stimulation as described by other investigators. This variability was confirmed in the present study and may reflect the fact that the field of depolarisation of the stimulator probes increases as the stimulus intensity is increased. ${ }^{9}$ The effect of the increase in the size of the field of depolarisation would be most evident when stimulating the dorsum of the hand where the superficial radial nerve branches are dispersed, in contrast to the forearm where they travel in one bundle. On the dorsum of the hand a slight increase in the field of the stimulating electrodes may produce stimulation of other terminal branches in addition to the one passing over the tendon of the extensor pollicis longus (fig 4).

The results from the study of normal subjects show that distal latency increases with age. Dylewska $^{3}$ has noted that distal latency increased in subjects over the age of 35 years, while Feibel and Foca $^{4}$ report prolongation in those over 50 years. Although the mean latency increased with each decade in this study, the upper limit of normal was $2.3 \mathrm{~ms}$ in subjects less than 30 years of age and $2.4 \mathrm{~ms}$ for all subjects who were older than 30 years.
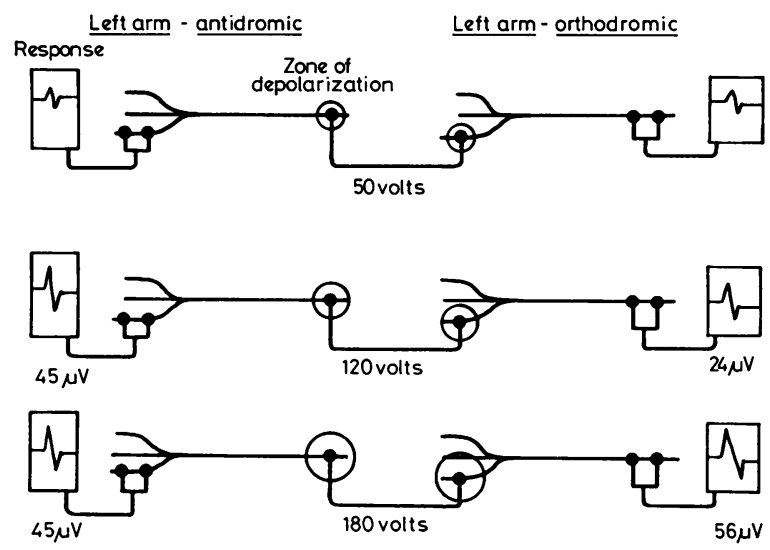

Fig 4 Effect of extent of stimulation field on orthodromic radial sensory response. 
The maximum difference between extremities of normal subjects with respect to amplitude was $50 \%$ and with respect to peak latency, $10 \%$. These limits are useful in the detection of unilateral nerve lesions and are similar to the magnitude of differences between the extremities reported in ulnar and median sensory conduction studies. ${ }^{10}$

The amplitudes of response of the radial nerve elicited by this method were larger than those obtained from the median and ulnar nerves. Because of the ease of study and relative rarity of radial injury from compression, radial sensory studies should prove useful for the evaluation of patients suspected of having peripheral neuropathy.

\section{References}

1 Downie AW, Scott TR. Radial nerve conduction studies. Neurology 1964; 14:839-43.

2 Downie AW, Scott TR. Improved technique for radial nerve conduction studies. J Neurol Neuro- surg Psychiatry 1967; 30:332-6.

3 Dylewska D. Conduction in sensory nerve fibres of the radial nerve in healthy subjects. Neurol Neurochem (Pol) 1974; 8:513-9.

4 Feibel A, Foca FJ. Sensory conduction of the radial nerve. Arch Phys Med Rehab 1974; 55: 314-6.

5 Trojaberg W, Sindrup EH. Motor and sensory conduction in different segments of the radial nerve in different subjects. $J$ Neurol Neurosurg Psychiatry 1969; 32:354-9.

6 Gassel MM, Diamantopoulos E. Pattern of conduction times in the distribution of the radial nerve. Neurology 1964; 14:222-31.

7 Jebsen RL. Motor conduction velocity of distal radial nerve. Arch Phys Med 1966; 47:12-6.

8 Shahani B et al. Sensory nerve action potentials in radial nerve. Arch Phys Med Rehab 1967; 48: 602-5.

9 Wiederholt WC. Stimulus intensity and site of excitation in human median nerve sensory fibres. J Neurol Neurosurg Psychiatry 1975; 38:1187-9.

10 Felsenthal G. Median and ulnar distal motor and sensory latencies in the same normal subject. Arch Phys Med Rehab 1977; 58:297-302. 